\title{
PENGARUH METODE SAS (STRUKTURAL ANALITIK SINTETIK) TERHADAP \\ KEMAMPUAN MENULIS SISWA DALAM PEMBELAJARAN BAHASA INDONESIA DI KELAS 1 SDN 195/VIII WIROTHO AGUNG
}

\author{
Dea Fajar Ningsih ${ }^{1}$, Maldin Ahmad Burhan², Muhammad Subhan3 \\ ${ }^{1}$ Mahasiswa Universitas Dharmas Indonesia \\ ${ }^{2,3}$ Dosen Universitas Dharmas Indonesia \\ Email: deafajarningsih16@gmail.com
}

Received: July 15, 2020 Revised: July 25, 2020 Accepted: Agustus 14, 2020

\begin{abstract}
ABSTRAK
Penelitian ini dilatarbelakangi oleh kurangnya kemampuan menulis siswa. Upaya untuk mengatasi permasalahan tersebut diperlukan metode Metode SAS (Struktural Analitik Sintetik). Penelitian ini bertujuan untuk mengetahui pengaruh metode SAS (Struktural Analitik Sintetik) terhadap kemampuan menulis siswa pada mata pelajaran bahasa indonesia. Penelitian ini menggunakan quasi eksperimental design dengan nonequivalent control group design. Populasi dalam penelitian adalah seluruh siswa kelas 1 SDN 195/VIII Wirotho Agung yang terdiri dari dua kelas. Sampel dalam penelitian ini diambil dengan menggunakan purposive sampling. Teknik pengumpulan data di ambil dengan memberikan pretest dan posttest berupa tes tertulis. Berdasarkan hasil perhitungan diperoleh dari kedua sampel kelompok bersifat normal dan homogen, sehingga dilakukan uji t. maka diperoleh nilai signifikasi (sig) yaitu 0,030 dengan probalitas 0,05, maka diperoleh nilai signifikasi (sig) < probalitas $=0,030<0,05$. Karena nilai signifikasi $(\mathrm{sig})<$ probalitas $=0,030<0,05$, maka Ho ditolak dan $\mathrm{Ha}$ diterima. Perbandingan kedua angka diatas menunjukan bahwa terdapat pengaruh pada penerapan metode Struktural Analitik Sintetik (SAS) terhadap kemampuan menulis siswa kelas 1 di SDN 195/VIII Wirotho Agung.
\end{abstract}

Kata Kunci: Metode SAS, kemampuan menulis, Pembelajaran Bahasa Indonesia.

\begin{abstract}
This research is attracted by the lack of students' writing skills. In order to overcome these problems, it requires the SAS (Synthetic Structural Analytical) method. This study aims to determine the effect of the SAS (Structural Analytic Synthetic) method on students' writing skills in Indonesian subjects. This study uses a quasi-experimental design with a nonequivalent control group design. The population in this study were all grade 1 students of SDN 195/VIII Wirotho Agung which consisted of two classes. The sample in this study was taken using purposive sampling. Data collection techniques were taken by giving a pretest and posttest in the form of a written test. Based on the calculation results obtained from the two groups of samples are normal and homogeneous, so that the test was carried out. then the significance value ( $\mathrm{sig}$ ) is 0.030 with a probability of 0.05 , then the significance value $(\mathrm{sig})<$ probability $=0.030<0.05$. Because the significance value $(\mathrm{sig})<$ probability $=0.030$ $<0.05$, then Ho is rejected and $\mathrm{Ha}$ is accepted. The comparison of the two figures above
\end{abstract}


shows that there is an influence on the application of the Structural Analytic Synthetic (SAS) method on the writing ability of grade 1 students at SDN 195/VIII Wirotho Agung.

Keywords: SAS method, writing ability, Indonesian language learning.

\section{PENDAHULUAN}

Pendidikan adalah proses belajar mengajar yang dilakukan oleh sekelompok individu untuk memperoleh bekal pengetahuan dan pembetukan etika serta menambah keterampilan dalam sekelompok individu (siswa) dan dibimbing oleh individu lainnya (guru). Pendidikan adalah bekal dan kebutuhan yang harus dimiliki siswa untuk mengembangkan kecapakapan dan potensi yang dimiliki siswa (Rahmadani, 2019). Salah satu proses untuk mencapai potensi itu adalah dengan menggunaka bahasa, dalam konteks pendidikan salah satunya melalui bahasa Indonesia. Bahasa Indonesia sebagai alat komunikasi yang digunakan oleh anggota masyarakat dari berbagai suku dan budaya serta bahasa yang berbeda-beda dari setiap daerah, sehingga dapat berkomunikasi dan menyampaikan informasi dengan baik menggunakan bahasa Indonesia. Dalam pembelajaran bahasa Indonesia dengan fokus menulis guru memadukan keterampilan siswa dengan keterampilan menyimak/ mendengarkan, membaca, atau dipadukan dengan pembelajaran kebahasaan lain seperti kosa kata, struktur, ejaan, dan sebagainya. Pembelajaran menulis permulaan bagi siswa SD kelas rendah terbagi ke dalam dua tahap yaitu : tahap mengenalan huruf alfabet sehingga akan memudahkan siswa untuk menulis, latihan menulis huruf seperti huruf alfabet dan a,i,u,e,o ataupun kata-kata sederhana (Satriawan, Hambali, and Muktadir, 2019).

Kondisi nyata yang terjadi sekarang terkait hasil belajar siswa kelas 1 SD tentang kemampuan menulis siswa kurang begitu maksimal. Dari 25 yang terdiri 13 siswa laki-laki dan 12 siswa perempuan, 3 siswa yang sudah bisa menulis huruf, kata, dan kalimat dengan baik, meskipun masih tahap permulaan, 3 siswa yang belum bisa menulis huruf, dan 19 siswa yang bisa menulis kata sederhana tetapi masih perlu bimbingan karena tidak menggunakan spasi dan terdapat huruf yang tertinggal. Hasil observasi yang dilakukan penulis di SDN 195/VIII Wirotho Agung kelas 1 adalah melihat permasalahan pada proses pembelajaran yaitu saat menulis siswa belum dapat membedakan huruf yang hampir sama. Dikarenakan belum terlalu lancar membaca dan mengenal huruf, sehingga saat menulis banyak huruf yang tertinggal dan tidak menggunakan jarak atau spasi saat menulis.

Berdasarkan masalah di atas, maka peneliti memberikan solusi dengan metode Struktural Analitik Sintetik (SAS). Metode Struktural Analitik Sintetik (SAS) pada dasarnya 
merupakan metode yang di gunakan bagi peserta didik yang baru belajar (pemula) untuk menulis dan membaca (Rahmadani, 2019). Agar siswa dapat memiliki kemampuan menulis dalam pembelajaran bahasa Indonesia maka guru dapat melakukan beberapa hal seperti : menuliskan dengan huruf yang panjang kebawah seperti $\mathrm{P}$ dan huruf yang panjang ke atas seperti B di papan tulis. Menulis dengan kata-kata sederhana seperti bola dan memberi tanda strip (-). kemudian guru juga mendakati siswa yang belum menulis untuk memberi tahu huruf yang seharus nya di tulis, guru juga berjalan untuk melihat tulisan siswa apakah ada yang salah atau tidak. Jika terdapat siswa yang tidak mengetahui huruf yang akan di tulis atau belum mengetahui bagaimana huruf $\mathrm{P}$ maka guru akan menuliskan bentuk $\mathrm{P}$ di papan tulis, atau membimbing di buku siswa dengan memegang tangan nya dan membimbing untuk menuliskan huruf P. Contoh dari penggunaan metode SAS dapat dilakukan dengan guru menulis di papan tulis kata-kata sederhana seperti “ ini mobil” menjadi " I ni mo bil” atau dapat juga di tulis dengan " i-ni mo-bil".

Beberapa penelitian pendukung yang menjadi rujukan dalam penelitian ini adalah penelitian terdahulu yang memberikan bukti empiris terkait implementasi metode SAS (Struktural Analitik Sintetik) yaitu : Hasil penelitian (Sari,dkk.2020) yang menyatakan bahwa hasil penelitian ini menunjukan bahwa ada pengaruh metode struktural analitik sitentik terhadap kemampuan menulis permulaan. Dari analisis data diperoleh bahwa uji hipotesis kemampuan menulis permulaan berupa yang pertama uji $\mathrm{t}$ berpasangan pada kelas eksperimen diperoleh thitung 15,45 dan ttabel 2,0518 dengan kriteria thitung $\leq$-ttabel maka Ho diterima. Sedangkan untuk kemampuan menulis permulaan di kelas kontrol diperoleh thitung $-4,16$ dan dan ttabel 2,0518 dengan kriteria thitung $\leq$-ttabel maka Ho diterima.

Berdasarkan permasalah di atas, maka peneliti tertarik untuk melakukan penelitian eksperimen yang berjudul "Pengaruh metode SAS (Struktural Analitik Sintetik) terhadap kemampuan menulis siswa dalam pembelajaran bahasa Indonesia di kelas 1 SDN 195/VIII Wirotho Agung".

\section{METODE}

Jenis penelitian yang digunakan adalah penelitian kuantitatif dalam bentuk metode quasi eksperimen design dengan model nonequivalent control group design. Menurut (Sugiyono, 2017) Desain ini hampir sama dengan pretest-posttest control group design, hanya saja pada desain ini kelompok eksperimen maupun kelompok kontrol tidak dipilih secara random. Adapun yang menjadi populasi dalam penelitian ini adalah seluruh siswa kelas 1 di SDN 195/VIII Wirotho Agung tahun ajaran 2020/2021 yang terdiri dari 45 siswa dari dua 
kelas. Teknik sampel yang digunakan dalam penelitian ini adalah Purposive Sampling. Peneliti menggunakan kelas kontrol dan kelas eksperimen dalam penelitian ini, untuk 1A sebagai kelas eskperimen sebanyak 11 siswa dan 1B sebagai kelas kontrol sebanyak 10 siswa.

Instrument penelitian merupakan alat yang digunakan mengukur fenomena alam maupun sosial yang dilihat dari hal-hal yang akan di teliti oleh individu untuk memperoleh informasi (Sugiyono, 2017). Instrumen yang digunakan untuk memperoleh data yaitu instrument test berbentuk soal essay, dimana soal tersebut sudah di uji menggunakan Uji Validitas, Uji Reabilitas, Tingkat Kesukaran dan Daya Pembeda. Teknik pengumpulan data berupa tes awal pretest, dan tes akhir posttest. Teknik dalam analisis data dalam penelitian kuantitatif menggunakan statistic dengan uji prasyarat yaitu uji normalitas, uji homogenitas dan uji hipotesis.

\section{HASIL PENELITIAN DAN PEMBAHASAN}

Hasil awal ketuntasan belajar kelas eksperimen dan kelas kontrol berdasarkan hasil nilai pretest yang dilakukan sebelum kegiatan pembelajaran. Proses pembelajaran kedua kelas mendapat perlakuan yang berbeda yaitu kelas eksperimen dengan menggunakan metode pembelajaran Struktural Analitik Sintetik (SAS) sedangkan kelas kontrol dengan metode konvensional. Setelah proses pembelajaran berakhir, kelas eksperimen dan kelas kontrol diberi tes akhir (posttest) yang sama.

Berdasarkan analisis data pretest dan posttest siswa diperoleh nilai rata-rata pretest kelas eksperimen 66.3 dan kelas kontrol diperoleh nilai rata-rata pretest 68. Sedangkan nilai posttest kelas eksperimen 76,25 dan kelas kontrol diperoleh nilai rata-rata posttest 66.

\section{Analisis Data}

Uji normalitas dilakukan untuk menentukan apakah kelas yang diteliti memiliki bagian normal atau tidak pada kemampuan menulis peserta didik. Uji normalitas dilakukan dengan menggunakan bantuan program SPSS. Seperti tabel di bawah ini.

\section{Tabel 1 Hasil Perhitungan Uji normalitas}

\begin{tabular}{|c|c|c|c|c|}
\hline & \multirow[b]{2}{*}{ Kelas } & \multicolumn{3}{|c|}{ Shapiro-Wilk } \\
\hline & & Statistic & $\mathrm{df}$ & Sig. \\
\hline \multirow{2}{*}{$\begin{array}{l}\text { hasil belajar } \\
\text { siswa }\end{array}$} & pretest eksperimen & .898 & 10 & .209 \\
\hline & posttest eksperimen & .919 & 11 & .311 \\
\hline
\end{tabular}




\begin{tabular}{|c|c|c|c|}
\hline pretest kontrol & .920 & 11 & .321 \\
\hline posttest kontrol & .967 & 11 & .850 \\
\hline
\end{tabular}

Sumber : SPSS 22

Berdasarkan table 1 menunjukan sampel yang digunakan < 50 maka data yang digunakan adalah Shapiro-Wilk. Nilai Sig pretest kelas eksperimen = 0,209 dengan alfa 5\% atau 0,05 maka nilai Sig $=0,209>0,05$. Nilai Sig posttest kelas eksperimen $=0,311$ dengan alfa 5\% atau 0,05 maka nilai Sig $=0,311>0,05$ maka data berdistribusi normal. Sedangkan Nilai Sig pretest kelas kontrol $=0,321$ dengan alfa 5\% atau 0,05 maka nilai Sig = 0,321>0,05. Nilai Sig posttest kelas kontrol $=0,850$ dengan alfa 5\% atau 0,05 maka nilai Sig $=0,850>0,05$ maka data berdistribusi normal.

Untuk mengetahui homogenitas dari kelas eksperimen dan kontrol apakah memiliki persamaan dalam kemampuan menulisnya dalam kedua kelas, maka dilaakukan uji homogenitas. Perhitungan uji homogenitas pada penelitian ini dibantu program SPSS. Seperti tabel di bawah ini.

Tabel 2 Hasil Perhitungan Uji homogenitas

\begin{tabular}{|c|c|c|c|c|c|}
\hline & & Statis & df1 & $\mathrm{df} 2$ & Sig. \\
\hline \multirow{4}{*}{$\begin{array}{l}\text { hasil } \\
\text { belajar } \\
\text { siswa }\end{array}$} & Based on Mean & .553 & 1 & 20 & .466 \\
\hline & Based on Median & .353 & 1 & 20 & .559 \\
\hline & $\begin{array}{l}\text { Based on Median and with } \\
\text { adjusted df }\end{array}$ & .353 & 1 & $\begin{array}{l}17.96 \\
2\end{array}$ & .560 \\
\hline & Based on trimmed mean & .358 & 1 & 20 & .557 \\
\hline
\end{tabular}

Sumber : SPSS 22

Berdasarkan tabel 2 menunjukan bahwa kedua kelompok sampel bersifat homogen. Hal ini dapat dilihat berdasarkan hasil signifikan dari kedua kelompok yaitu : 0.466. Dimana data yang bersifat homogen taraf signifikannya harus besar dari 0,05.

\section{Pengujian Hipotesis}

Uji ini dilakukan dengan menggunakan rumus t-test. Tujuan uji t-test ini digunakan untuk mengetahui ada atau tidaknya perbedaan yang sangat berpengaruh untuk 
membandingkan apakah kedua kelas memiliki kesamaan atau perbedaan yang dibantu dengan program SPSS. Seperti tabel di bawah ini.

Tabel 3 Pengujian Hipotesis

\begin{tabular}{|c|c|c|c|c|c|c|c|c|c|c|}
\hline & \multicolumn{2}{|c|}{$\begin{array}{l}\text { Levene's Test } \\
\text { for Equality of } \\
\text { Variances }\end{array}$} & \multicolumn{7}{|c|}{ t-test for Equality of Means } \\
\hline & & \multirow[b]{2}{*}{$\mathrm{F}$} & \multirow[b]{2}{*}{ Sig. } & \multirow[b]{2}{*}{$\mathrm{t}$} & \multirow[b]{2}{*}{ df } & \multirow{2}{*}{$\begin{array}{l}\text { Sig. } \\
(2- \\
\text { taile } \\
\text { d) }\end{array}$} & \multirow{2}{*}{$\begin{array}{l}\text { Mean } \\
\text { Differen } \\
\text { ce }\end{array}$} & \multirow{2}{*}{\begin{tabular}{|l} 
Std. \\
Error \\
Differenc \\
e
\end{tabular}} & \multicolumn{2}{|c|}{$\begin{array}{ll}95 \% & \text { Confidence } \\
\text { Interval of the } \\
\text { Difference }\end{array}$} \\
\hline & & & & & & & & & Lower & Upper \\
\hline $\begin{array}{l}\text { hasil } \\
\text { belajar } \\
\text { siswa }\end{array}$ & $\begin{array}{l}\text { Equal variances } \\
\text { assumed }\end{array}$ & 5.530 & .030 & $\begin{array}{l}- \\
1.74 \\
9\end{array}$ & 19 & .096 & -10.364 & 5.926 & -22.766 & 2.039 \\
\hline
\end{tabular}

Berdasarkan table 3, diperoleh nilai signifikasi (sig) yaitu 0,030 dengan probalitas 0,05, maka diperoleh nilai signifikasi $(\mathrm{sig})<$ probalitas $=0,030<0,05$. Karena nilai signifikasi $(\mathrm{sig})<$ probalitas $=0,030<0,05$, maka Ho ditolak dan Ha diterima. Perbandingan kedua angka diatas menunjukan bahwa terdapat pengaruh pada penerapan metode Struktural Analitik Sintetik (SAS) terhadap kemampuan menulis siswa kelas 1 di SDN 195/VIII Wirotho Agung.

\section{PEMBAHASAN}

Bahasa bagi manusia memiliki peranan penting dalam kehidupan sehari-hari yaitu sebagai sarana komunikasi. Dimana manusia dapat berkomunikasi dengan individu lainnya menggunakan bahasa nasional. Bahasa adalah sistem lambang bunyi yang bersifat mana suka (arbitrer) yang dipergunakan oleh para anggota kelompok masyarakat untuk bekerja sama, berkomunikasi secara langsung dan mengidentifikasi diri (Rosdiana, 2017). Bahasa Indonesia merupakan bahasa Nasional yang dipakai secara luas dan dapat dijadikan media menyampaikan informasi. Pembelajaran bahasa Indonesia menekankan empat keterampilan berbahasa seperti keterampilan; menyimak, berbicara, membaca dan menulis agar mampu membantu indvidu berkomunikasi dengan baik komunikasi lisan maupun komunikasi lewat bahasa tulisan (Jimi, dkk. 2014). Keempat aspek keterampilan berbahasa tersebut saling berkaitan satu sama lain, sehingga merupakan satu kesatuan utuh dan yang tersusun, hal ini 
dapat diartikan bahwa keterampilan berbahasa yang satu dengan yang lainnya menjadi sebuah dasar keterampilan (Priatna dan Setyarini 2019).

Menulis merupakan kegiatan berbahasa dengan menyampaikan pesan secara tidak langsung dan untuk menciptakan suatu informasi dengan media pena dan buku (Khoridah, 2019). Belajar menulis memerlukan waktu yang lama untuk itu menulis diajarkan sejak siswa usia dini. Oleh karena itu, dalam menulis siswa harus menguasi beberapa unsur kebahasaan dari apa yang di tuliskan agar tersampaikan pesan gagasan dan ide yang terkandung di dalam nya. Sebelum menulis siswa harus terlebih dahulu mengenal lambang-lambang bunyi dari AZ. Permulaan dalam menulis dapat dilakukan dengan menuliskan huruf-huruf vokal dan konsonan, sehingga dapat menulis huruf, angka dan kalimat sederhana dengan benar (Khoridah, 2019). Kegiatan menulis menghendaki penguasaan unsur kebahasaan yang menyangkut; tata bahasa yang benar, ejaan dan tanda baca, serta penulisan gagasan kedalam bahasa yang tepat, teratur dan lengkap, agar komunikasi lewat lambang tulis dapat dipahami sebagaimana yang diharapkan (Mahmud, 2017).

Berdasarkan kondisi awal diketahui bahwa pada proses pembelajaran yaitu saat menulis siswa belum dapat membedakan huruf yang hampir sama, huruf yang tertinggal dan tidak menggunakan spasi saat menulis. Oleh karena itu penulis menggunakan metode Struktural Analitik Sintetik (SAS) untuk meningkatkan kemampuan menulis siswa. Metode Struktural Analitik Sintetik (SAS) pada dasarnya merupakan metode yang di gunakan bagi pemula untuk belajar menulis dan membaca (Rahmadani, 2019). Metode ini dikembangkan dalam pengajaran membaca dan menulis di Sekolah Dasar.

Sebelum pembelajaran dimulai, dengan menggunakan metode Struktural Analitik Sintetik (SAS) untuk kelas eksperimen dan metode konvensional untuk kelas kontrol, terlebih dahulu diadakan pretest pada siswa kelas 1 A (kelas eksperimen) dan kelas 1B (kelas kontrol) mengenai tema peritiwa alam subtema peristiwa siang dan malam untuk mengetahui kondisi awal kedua kelas tersebut sebelum memperoleh pelajaran.

Hasil awal ketuntasan belajar kelas eksperimen dan kelas kontrol berdasarkan hasil nilai pretest yang dilakukan sebelum kegiatan pembelajaran. Proses pembelajaran kedua kelas mendapat perlakuan yang berbeda yaitu kelas eksperimen dengan menggunakan metode pembelajaran Struktural Analitik Sintetik (SAS) sedangkan kelas kontrol dengan metode konvensional. Kelas eksperimen yang terdiri dari 11 peserta didik dan kelas kontrol terdiri dari 10 peserta didik. Setelah proses pembelajaran berakhir, kelas eksperimen dan kelas kontrol diberi tes akhir (posttest) yang sama. 
Berdasarkan hasil dari uji hipotesis penelitian menunjukan bahwa terdapat adanya pengaruh dalam pembelajaran menggunakan metode SAS (Struktural Analitik Sintetik) terhadap kemampuan menulis siswa dalam pembelajaran bahasa Indonesia di kelas 1 SDN 195/VIII Wirotho Agung. Hal ini terlihat dari hipotesis yang ditemukan yaitu nilai signifikasi (sig) yaitu 0,030 dengan probalitas 0,05, maka diperoleh nilai signifikasi (sig) < probalitas = $0,030<0,05$. Karena nilai signifikasi $(\mathrm{sig})<$ probalitas $=0,030<0,05$, maka Ho ditolak dan Ha diterima. Perbandingan kedua angka diatas menunjukan bahwa terdapat pengaruh yang signifikansi pada penerapan metode Struktural Analitik Sintetik (SAS) terhadap kemampuan menulis siswa.

Hal ini sesuai dengan penelitian yang dilakukan oleh Penelitian yang dilakukan oleh (Naitili,dkk. 2019) yang berjudul "Penerapan Metode Struktural Analitik Sintetik untuk Meningkatkan Keterampilan Menulis Permulaan Siswa Sekolah Dasar”. Hasil penelitian ini menunjukan bahwa menggunakan metode SAS keterampilan menulis permulaan siswa setelah dibelajarkan meningkat pada setiap siklus. Hal ini ditunjukkan dengan hasil penelitian yang telah dilakukan di SD Katolik In'ane di mana rata-rata persentase aktivitas siswa pada siklus I $60.33 \%$ berkualifikasi cukup, meningkat pada siklus II $75.42 \%$ berkualifikasi baik dan meningkat pada siklus III $82.42 \%$ berkualifikasi sangat baik. Perolehan rata-rata persentase keberhasilan aktivitas guru juga mengalami peningkatan yaitu pada siklus I $69.35 \%$ berkualifikasi cukup kemudian mengalami peningkatan pada siklus II $81.55 \%$ dan siklus III $88.69 \%$ dengan kualifikasi sangat baik. Adapun rata-rata persentase keberhasilan keterampilan menulis permulaan siswa pada siklus I $53.58 \%$ berkualifikasi cukup mengalami peningkatan pada siklus II $68.67 \%$ dan siklus III 79.92\% dengan kualifikasi baik.

\section{KESIMPULAN}

Berdasarkan hasil penelitian yang dilakukan di SDN 195/VIII Wirotho Agung, Kab. Tebo dapat disimpulkan bahwa : kemampuan menulis siswa kelas eksperimen dengan menggunakan metode Struktural Analitik Sintetik (SAS) memperoleh nilai rata-rata 76,25 sedangkan kelas kontrol yang tidak menggunakan metode tersebut memperoleh rata-rata 66. Hasil Penggunaan metode Struktural Analitik Sintetik (SAS) dapat meningkatkan kemampuan menulis siswa, dilihat dari nilai signifikasi (sign) yaitu 0,030 dengan probalitas 0,05, maka diperoleh nilai signifikasi $($ sign $)<$ probalitas $=0,030<0,05$. maka Ho ditolak dan Ha diterima. 
Berdasarkan hal tersebut berarti terdapat terdapat pengaruh yang signifikansi pada penerapan metode Struktural Analitik Sintetik (SAS) terhadap kemampuan menulis siswa kelas 1 di SDN 195/VIII Wirotho Agung.

\section{DAFTAR PUSTAKA}

Jimi, Kd, Kusuma Dewi, Ign I.Wyn Suwatra, and Ni Wyn Arini. 2014. "Penggunaan Metode Stuktur Analitik Sintetik (Sas)Untuk Meningkatkan Kemampuan Membaca Menulis Permulaan Pada Siswa Kelas I Sd Negeri 7 Bungkulan Jurusan Pendidikan Guru Sekolah Dasar , Fip Universitas Pendidikan Ganesha E-Journal Mimbar Pgsd Univers.” E-Journal MIMBAR PGSD Universitas Pendidikan Ganesha 2(1).

Khoridah, Faizatul. 2019. "Analisis Penerapan Metode Sas (Struktural Analitik Sintetik) Dalam Kemampuan Menulis Permulaan." Journal for Lesson and Learning Studies 2(3):396-403.

Mahmud, H. 2017. "Upaya Meningkatakan Keterampilan Menulis Dengan Teknik RCG (Reka Cerita Gambar) Pada Siswa Kelas VI SDN Rengkak Kecamatan Kopang, Kabupaten. Lombok Tengah Tahun Pelajaran 2017/2018.” JISIP 1(2):32-46.

Naitili, Cornelia Amanda, I.Made Suardana, and M. Ramli. 2019. "Penerapan Metode Struktural Analitik Sintetik Untuk Meningkatkan Keterampilan Menulis Permulaan Siswa Sekolah Dasar." 660-67.

Priatna, Asep, and Ghea Setyarini. 2019. “1 , 2 1,2.” Pendas : Jurnal Ilmiah Pendidikan Dasar IV:147-59.

Rahmadani, Nunu. 2019. "Peningkatan Keterampilan Menulis Permulaan Melalui Penerapan Metode Struktur Analitik Sintetik ( Sas )." Journal of Theaching and Learning Research 1(1):33-40.

Rosdiana, Yusi.dk. 2017. Bahasa Dan Sastra Indonesia Di SD. 1st ed. Jakarta: Universitas Terbuka.

Sari, Yunita, Ratri Dyah Luvita, Andarini Permata Cahyaningtyas, Vina Iasha, and Bramianto Setiawan. 2020. "Pengaruh Metode Pembelajaran Struktural Analitik Sitentik Terhadap Kemampuan Menulis Permulaan Di Sekolah Dasar Y.” Jurnal Basicedu 4(4):1124-32.

Satriawan, Sabar, Daimun Hambali, and Abdul Muktadir. 2019. "Studi Deskriptif Pembelajaran Tematik Dalam Membaca Dan Menulis Permulaan Dengan Menggunakan Metode Struktural Analitik Sentesis (SAS )." JP3D (Jurnal Pembelajaran Dan Pengajaran Pendidikan Dasar) 2(2):177-89.

Sugiyono. 2017. Metode Penelitian Kuantitatif, Kualitatif Dan $R \&$ D. Bandung: Alfabeta. 